\title{
Improving Carbon Product Yields in Biocarbon Production by Combining Pyrolysis and Anaerobic Digestion
}

\author{
Cornelis van der Wijst, ${ }^{\mathrm{a}, *}$ Nirmal Ghimire, ${ }^{\mathrm{b}}$ Wenche Hennie Bergland, ${ }^{\mathrm{b}}$ Kai Toven, ${ }^{\mathrm{a}}$ \\ Rune Bakke, ${ }^{\mathrm{b}}$ and Øyvind Eriksen ${ }^{\mathrm{a}}$
}

\begin{abstract}
Solid carbon is an important raw material in industrial processes. Most of the charcoal produced today is via conventional carbonization, which suffers from huge carbon losses due to system inefficiency. Intermediate pyrolysis is principally similar to conventional carbonization and produces biocarbon while capturing the off gasses; among these off gasses is aqueous condensate, which is difficult to utilize due to the high water content and low energy content. This fraction can contain up to $25 \%$ of the carbon from feedstock, so utilization of this fraction is important for good overall carbon balance. Anaerobic digestion can be a promising tool for utilizing the carbon in the aqueous condensate by converting it into biomethane. Here, birch and spruce wood were pyrolyzed and the biomethane potential for the aqueous condensates was tested. The mass and carbon balances of the pyrolysis products of birch and spruce at two pyrolysis temperatures were performed, and biocarbon carbon yields ranging from $42 \%$ to $54 \%$ were obtained. Anaerobic digestion of the aqueous phases collected from the pyrolysis process was performed, with carbon recovery yields between $44 \%$ and $59 \%$. A total carbon recovery of $77.8 \%$ to $85.7 \%$ was obtained, and the primary carbon losses were identified.
\end{abstract}

Keywords: Biocarbon; Pyrolysis-anaerobic digestion combination; Increased carbon yield

Contact information: $a$ : RISE PFI AS, Høgskoleringen 6B, NO-7491 Trondheim, Norway; $b$ : Department of Process, Energy and Environmental Technology, University of South-Eastern Norway, Kjølnes ring 34, NO 3918 Porsgrunn, Norway; *Corresponding author: cornelis.vanderwijst@ rise-pfi.no

\section{INTRODUCTION}

In order to reduce consumption of fossil resources, efforts should be made towards providing new and renewable alternatives. The metallurgical industry requires a carbon material to act as a reducing agent and energy source, and a transition from fossil coal to renewable carbon would cause a huge reduction in global fossil $\mathrm{CO}_{2}$ emissions. Although many industrial processes already use charcoal, the majority of the charcoal produced today is still produced in traditional kilns, e.g., earth mound kilns in sub-Saharan Africa and "hot tail" kilns in Brazil (Pennise et al. 2001; Bailis et al. 2013). Usually, these traditional kilns do not have off gas utilization or recovery, resulting in large emissions of incomplete combustion products into the atmosphere, which has a larger global warming impact than the molar $\mathrm{CO}_{2}$ equivalent of the complete combustion products of the off gasses (Bailis 2009). In addition, these emissions are harmful to humans and can increase mortality and respiratory disease rates for populations close to the points of emission (Bailis et al. 2005).

Brazil is the largest charcoal producer in the world, and the main type of kiln used is the "hot tail" kiln (Bailis et al. 2013). Although they are more efficient than most earth- 
mound kilns used in sub-Saharan Africa, "hot tail" kilns have a reported maximum charcoal mass yield of $34.1 \%$ and a charcoal carbon yield of $52.1 \%$ (Pennise et al. 2001). This results in an approximate $65 \%$ and $50 \%$ loss in mass and carbon, respectively, due to system inefficiency by the venting of off gasses.

Modern pyrolysis, i.e., thermal decomposition without oxygen, is a simple yet powerful primary conversion technique and is fundamentally similar to charcoal production. Pyrolysis is used for a large variety of feedstocks; it has been a promising route for biomass utilization for a long time but has struggled to find commercial feasibility (Maschio et al. 1992). During the last few decades, the research focus on biomass pyrolysis has predominantly been on fast pyrolysis, with the aim of optimizing the bio-oil yield and quality (Bridgwater 2012). In recent years, emphasis on the co-production of bio-oil and biocarbon has increased, as the numerous applications and considerable environmental benefits of biocarbon have been recognized (Laird et al. 2009; Cha et al. 2016).

Intermediate pyrolysis is a relatively new genre within pyrolysis that balances the yield of biocarbon and bio-oil. Typically, $30 \mathrm{wt} \%$ of biocarbon is obtained from intermediate pyrolysis, which is in the upper range of traditional charcoal kiln yields, as opposed to the $12 \mathrm{wt} \%$ biocarbon yield with fast pyrolysis. The increased biocarbon yield is a result of the decrease in heating rates and increased reaction time when compared to the fast pyrolysis process. Fast pyrolysis processes its feedstock within seconds, while intermediate pyrolysis is usually completed within $30 \mathrm{~min}$ to $90 \mathrm{~min}$; "hot tail" kilns have a reported run time of 40 to $50 \mathrm{~h}$ (Pennise et al. 2001).

The bio-oil from intermediate pyrolysis usually phase separates into an organic condensate phase and an aqueous condensate phase, most likely due to secondary cracking of the vapours before condensation (Yang et al. 2014). This improves the viscosity and heating value of the organic condensate compared to the oil fast pyrolysis produces and can be used as an energy carrier. However, the aqueous condensate contains a considerable amount of water and water-soluble components, has low calorific value, and there is no direct area of application. This condensate fraction can still contain up to $25 \%$ of the carbon from the feedstock; thus it is important to utilise this fraction to ensure efficient carbon utilization and prevent the discharge of polluted water. A promising route for the utilization of the carbon in the aqueous condensate from intermediate pyrolysis (also called aqueous pyrolysis liquid (APL)) is biomethane production via anaerobic digestion (Hübner and Mumme 2015; Fabbri and Torri 2016; Feng and Lin 2017).

Anaerobic digestion (AD) is a biological process in which a consortium of microorganisms breaks down organic compounds to produce biogas (typically consisting of $50 \%$ to $75 \% \mathrm{CH}_{4}$ and $25 \%$ to $50 \% \mathrm{CO}_{2}$ ) in the absence of free oxygen. It is a mature, well-established, and robust technology in which mixed communities of organisms synergistically break down various easily degradable organic compounds, but it can also digest more complex, recalcitrant, and inhibiting compounds in low concentrations after some adaption time (Benjamin et al. 1984; Vasco-Correa et al. 2018). Biogas production via the anaerobic digestion of organic wastes is regarded as an effective waste treatment method as well as an energy production technology (Appels et al. 2008; Khalid et al. 2011). However, the anaerobic digestion of raw lignocellulosic biomass has proven difficult due to the recalcitrant nature of lignocellulosic biomass (Yang et al. 2015). It is nevertheless a promising technique for carbon recovery from aqueous side streams, e.g. APL, from intermediate pyrolysis. Although APL is a complex substrate with hundreds of compounds, with a few of these compounds considered toxic to the AD microorganisms, they are able to adapt to a wide range of chemical substance, which can be exploited to overcome the 
complexity of APL (Torri and Fabbri 2014). Moreover, the production of biomethane is a clean energy source that can be used as drop-in fuel after purification. This can be lucrative and is already available as a viable alternative as a transportation fuel (Appels et al. 2011).

Research on the AD of APL is still in its infancy. However, there is increased interest in pyrolysis as the research focuses on its use as a measure to handle the aqueous side stream (Hübner and Mumme 2015; Feng and Lin 2017). The application of APL in other fields has been hampered because of its low calorific value, acidity, chemical and thermal instability, and presence of complex and inhibitory compounds (Kan et al. 2017; Zhou et al. 2019). While the AD of APL from the pyrolysis of agricultural residues have been examined to some extent, little research has been done with wood as the feedstock where the pyrolysis process is focused on biochar production and quality.

The purpose of this work is to compare the carbon utilization of commercial charcoal production with the biocarbon production via intermediate pyrolysis combined with anaerobic digestion. The "hot tail" kiln process reported by Pennise et al. (2001) was chosen to be the benchmark process for commercial charcoal production, since it is the most common charcoal production method in Brazil. The pyrolysis of two different feedstocks at two different temperatures was performed along with the study of the biomethane potential of the corresponding aqueous condensates.

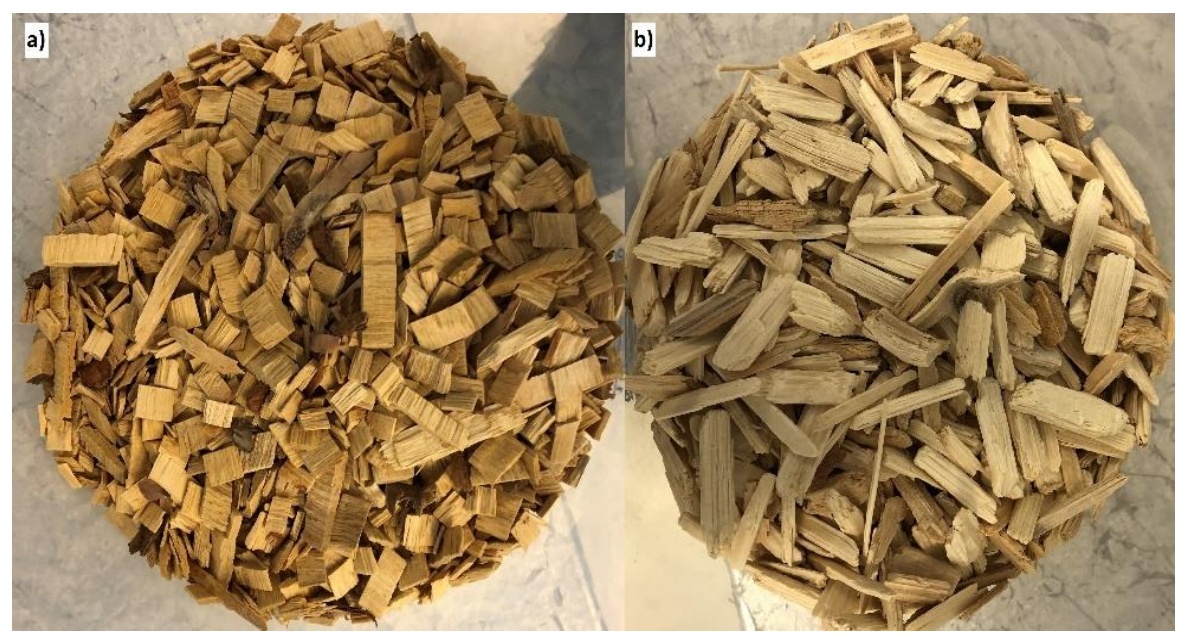

Fig. 1. The prepared raw materials before pyrolysis: a) birch; and b) spruce

\section{EXPERIMENTAL}

\section{Raw Materials}

Woodchips made from Norway spruce and birch wood were used for this experiment (Fig. 1). The Norway spruce chips were received from a Norwegian forestry company, with a dry matter content of $44.5 \%$. The sample was air dried to $93.9 \%$, and then hammer milled at 1000 RPM through a $19 \mathrm{~mm}$ hole screen and fractionated to a size between 13 and $5 \mathrm{~mm}$. The birch chips were received dry from a Norwegian sludge refining company, with a dry matter content of $93.4 \%$. The birch chips were fractionated to a size between 13 and $5 \mathrm{~mm}$. 


\section{Pyrolysis}

The wood chips were pyrolyzed in a pyrolysis development unit at RISE PFI AS, Trondheim, Norway (as shown in Fig. 2). The pyrolysis development unit consists of a stainless-steel fixed bed reactor $(5.6 \mathrm{~L})$, which is located in an oven. A heated gas transfer line connects the reactor with a condensation unit, which consists of two water-cooling condensers, an electrostatic precipitator (ESP), and a silica gel filter. The gas volume was measured continuously with a wet gas meter (WGM) and a micro-GC (Agilent Technology 490 Micro GC) measured the gas composition online. In addition, $\mathrm{N}_{2}$ gas was used as a purge gas during the entire experiment with a flow of $2 \mathrm{~L} / \mathrm{min}$. Typically, the reactor was filled with $400 \mathrm{~g}$ of feedstock and leak tested before the entire system was purged with $\mathrm{N}_{2}$ to remove oxygen. An oxygen-free atmosphere was confirmed with the micro-GC before starting the experiment. The heating time from room temperature to the two reaction temperatures $\left(400\right.$ and $550{ }^{\circ} \mathrm{C}$ ) was approximately $45 \mathrm{~min}$. The pyrolysis temperatures of 400 and $550{ }^{\circ} \mathrm{C}$ where chosen to cover the low and high end of typical intermediate pyrolysis temperatures. The reaction temperature was maintained for $90 \mathrm{~min}$ to ensure the complete and homogeneous carbonization of the feedstock. This resulted in 4 biocarbon samples, 4 condensate samples, and 4 sets of gas phase analysis. The vapours condensed in the water condenser naturally phase separated into an organic condensate phase and an aqueous condensate phase. The condensate was stored in the condensate bottles overnight before the top phase was decanted off.

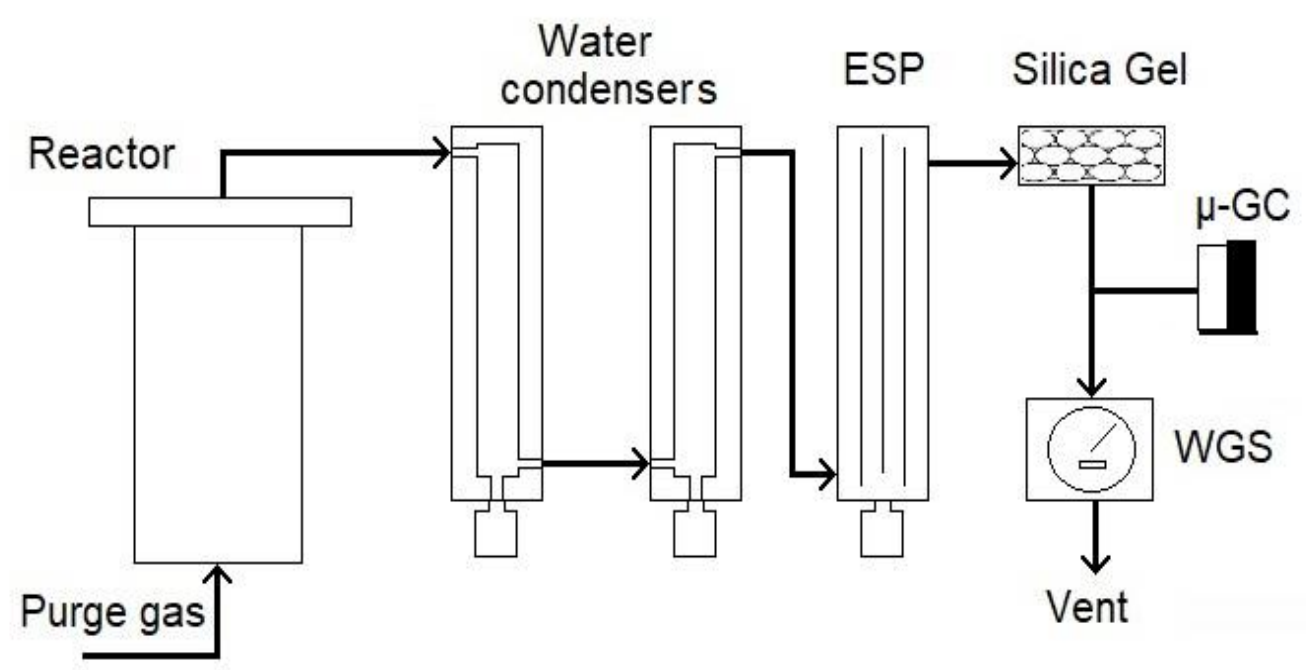

Fig. 2. Schematic detailing of setup of pyrolysis rig used for the pyrolysis experiments at RISE PFI

The silica gel filter before the $\mu-\mathrm{GC}$ is required to obtain a moisture-free gas for $\mu$ $\mathrm{GC}$ analyses. The silica gel turns black instead of white during operation, suggesting that more than moisture was absorbed in the silica gel filter. This is most likely bio-oil mist not condensed in the preceding condensers. Analysis of the absorbate of the silica gel filter is not possible, so it was assumed that the composition was similar to the aqueous condensate and included in the aqueous condensate in the results.

The water content was measured in all the condensate phases via a Karl-Fischer titration with a Mettler Toledo V20 Volumetric KF Titrator. The carbon contents of the feed, biocarbon, and condensate phases were analysed with a Thermo Scientific Flash 2000 $\mathrm{CHNS} / \mathrm{O}$ Analyzer. The aqueous condensates produced were used for anaerobic digestion. 


\section{Anaerobic Digestion}

The anaerobic digestion (AD) of APL as a substrate was performed as a batch test with an automatic methane potential test system II (AMPTS II, Bioprocess Control ${ }^{\circledR}$ Sweden $\mathrm{AB}$ ). This standardized laboratory set-up automatically determines the methane potential of any biodegradable material via the water displacement method.

The mesophilic granular sludge used as the inoculum was obtained from a mesophilic industrial AD reactor that treated paper mill effluent. The concentration of inoculum total solids (TS) and volatile solids (VS) were 181 and $119 \mathrm{~g} / \mathrm{L}$, respectively. The inoculum was degassed at $30{ }^{\circ} \mathrm{C}$ for at least $5 \mathrm{~d}$ before the experiment to reduce the gas production from the inoculum.

The APL substrate was added to a macro nutrient solution composed of $\mathrm{NH}_{4} \mathrm{Cl}$ $(44.48 \mathrm{~g} / \mathrm{L}),\left(\mathrm{NH}_{4}\right) \mathrm{H}_{2} \mathrm{PO}_{4}(5.3 \mathrm{~g} / \mathrm{L}),\left(\mathrm{NH}_{4}\right)_{2} \mathrm{HPO}_{4}(1.78 \mathrm{~g} / \mathrm{L}), \mathrm{MgCl}_{2} .6 \mathrm{H}_{2} \mathrm{O}(21.4 \mathrm{~g} / \mathrm{L})$, $\mathrm{CaCl}_{2} .2 \mathrm{H}_{2} \mathrm{O}(7.56 \mathrm{~g} / \mathrm{L})$, and $\mathrm{NaHCO}_{3}(100 \mathrm{~g} / \mathrm{L})$. The macro nutrient solution was added to the substrate to maintain a minimum COD to $\mathrm{N}$ to $\mathrm{P}$ ratio of 350 to 5 to 1 (Baeta et al. 2013).

Each APL sample was run in triplicate (as shown in Table 1) with an equal APL load in a standard $650 \mathrm{~mL}$ glass flasks (Kimax ${ }^{\circledR}$ kimble), with $200 \mathrm{~mL}$ of inoculum being added to create a working liquid volume of slightly greater than $200 \mathrm{~mL}$.

A blank sample, which only contained inoculum and distilled water, was also tested in triplicate. The gas produced from the blank sample was deducted from the gas produced from the APL samples to offset the gas produced via endogenous respiration of the microorganisms in the inoculum. The results thus represent only the gas produced from the tested samples.

The anaerobic reactors were initially purged with pure nitrogen for 5 to $7 \mathrm{~min}$ to remove all oxygen and ensure complete anaerobic condition. Then, AD was performed at a temperature of $35^{\circ} \mathrm{C}$ for $22 \mathrm{~d}$ with intermittent mixing for $10 \mathrm{~s}$ occurring every $\mathrm{h}$. The carbon dioxide content in the produced biogas was removed by passing it through $80 \mathrm{~mL}$ of $3 \mathrm{M}$ sodium hydroxide $(\mathrm{NaOH})$ mixed with a $0.4 \%$ thymolphthalein solution for each reactor. The methane produced from the AMPTS II was automatically provided as NmL (1 standard atmospheric pressure, $0{ }^{\circ} \mathrm{C}$, and zero moisture content) by the Bioprocess Control® software (AMPTS II, Version 5, Lund, Sweden). A more detailed description of this procedure is found in a study by Badshah et al. (2012).

Table 1. Experimental Design for the Anaerobic Digestion of Aqueous Pyrolysis Liquid

\begin{tabular}{|c|c|c|c|c|}
\hline Samples & Inoculum $(\mathrm{mL})$ & $\begin{array}{c}\text { APL Substrate } \\
(\mathrm{mL})\end{array}$ & Parallels & $\begin{array}{c}\text { Organic Loading } \\
(\mathrm{gCOD} \text { APL/Linoculum })\end{array}$ \\
\hline Birch $400^{\circ} \mathrm{C}$ & 200 & 1.4 & 3 & 5 \\
\hline Birch $550^{\circ} \mathrm{C}$ & 200 & 1.8 & 3 & 5 \\
\hline Spruce $400^{\circ} \mathrm{C}$ & 200 & 2.3 & 3 & 5 \\
\hline Spruce $550^{\circ} \mathrm{C}$ & 200 & 2.3 & 3 & 5 \\
\hline Control & 200 & $3\left(\right.$ dist. $\left.\mathrm{H}_{2} \mathrm{O}\right)$ & 3 & 0 \\
\hline
\end{tabular}

The chemical oxygen demand (COD) was measured according to US standard 5220D (APHA 1995). The samples were filtered through a $0.45 \mu \mathrm{m}$ pore size glass filter after sampling to measure the soluble COD (sCOD) using commercial kits (WTW ${ }^{\mathrm{TM}}$ ). 


\section{RESULTS AND DISCUSSION}

\section{The Effect of the Feedstock and Pyrolysis Temperature on the Carbon Yield}

The mass balances of the birch and spruce chips pyrolyzed at 400 and $550{ }^{\circ} \mathrm{C}$ are shown in Fig. 3. The mass recovery of the biocarbon, condensates, and gas phase added up to approximately $100 \%$ for each experiment, as intended by the design of the pyrolysis system. As expected, an increase in temperature resulted in a decrease in biocarbon yield and an increase in gas yield for both the birch and spruce feedstocks. The biocarbon yields from spruce were $32 \mathrm{wt} \%$ and $26 \mathrm{wt} \%$ for pyrolysis at a temperature of 400 and $550{ }^{\circ} \mathrm{C}$, respectively. This was higher than the biocarbon yields observed for birch $(28 \mathrm{wt} \%$ and 23 $\mathrm{wt} \%)$ at the same temperatures. This might be an inherent effect of the different feedstocks, as higher yields of charcoal are usually obtained from conifers than from deciduous trees (Wenzl 2012). The different shapes of the wood chips (Fig. 1) may also have influenced the biocarbon yields. Although sieved with the same sieves and in the exact same manner, the birch chips were thinner and shorter than the spruce chips (note, however, the treatment prior to fractionation was different for the two raw materials). The vapours generated within the spruce chips might have more time to form secondary biocarbon via decomposition before escaping the chips (Antal and Grønli 2003). No clear trend in the changes of the mass yield of the liquid condensate phases was observed with the temperature changes.

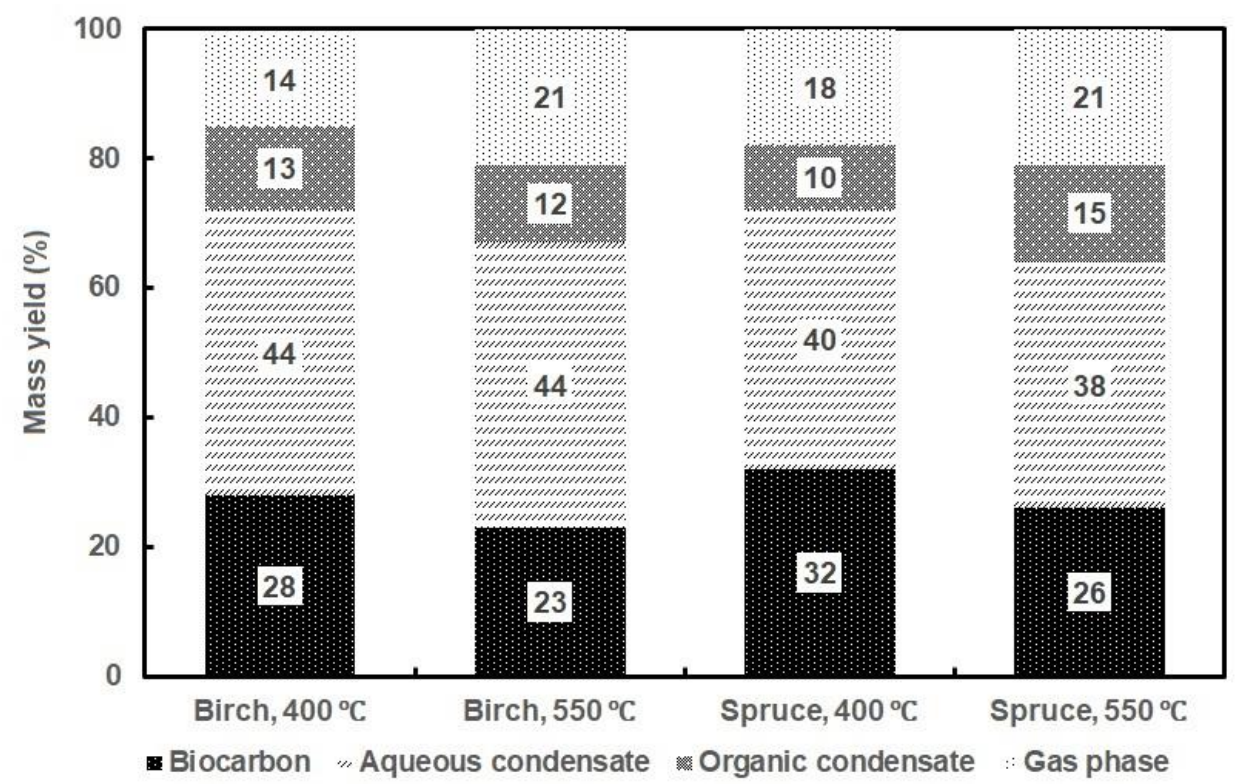

Fig. 3. Mass balances of the pyrolysis of birch and spruce feedstock

The carbon distribution from the pyrolysis of birch and spruce at 400 and $550{ }^{\circ} \mathrm{C}$ is shown in Fig. 4. The mass yields had similar trends to the biocarbon and gas carbon yields. An increase in the pyrolysis temperature resulted in a decrease in the carbon yield in the biocarbon and an increase in the carbon yield in the gas phase for both feedstocks. Similar decreases in the carbon content of the aqueous condensate as the pyrolysis temperature increased were observed for both feedstocks. For birch, a decrease from $26 \%$ to $23 \%$ in carbon was observed from the aqueous condensate as the temperature increased, while a decrease from $16 \%$ to $13 \%$ was observed in the aqueous condensate from spruce. However, 
no consistent effect on the carbon yields of the organic condensates was observed when the pyrolysis temperature was increased for either feedstock. The organic condensate from spruce had a considerable increase in carbon yield (from $15 \%$ to $21 \%$ ) as the pyrolysis temperature was increased, while a small decrease (from $15 \%$ to $14 \%$ ) in the carbon yield was observed in the organic condensate from birch.

The total recovered carbon of birch pyrolyzed at $550{ }^{\circ} \mathrm{C}$ was $96 \%$, compared to $98 \%$ of birch pyrolyzed at $400{ }^{\circ} \mathrm{C}$ and $99 \%$ of both spruce pyrolysis experiments. The slight reduction in carbon recovery can be due to condensation during the pyrolysis experiment or sample handling and carbon content analysis. The liquids produced during pyrolysis are inhomogeneous, which will increase the measuring uncertainties during carbon content analysis even though measures were taken to counteract this as much as possible.

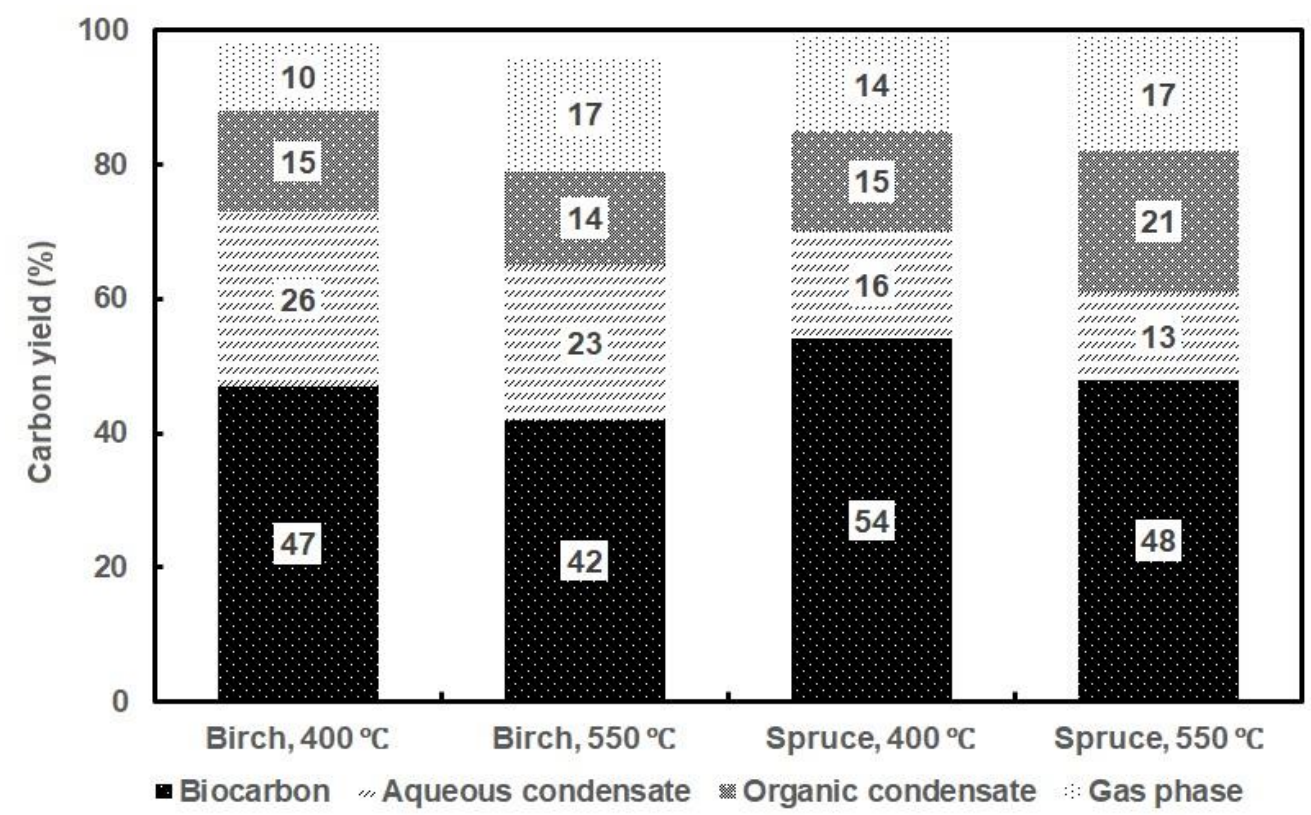

Fig. 4. Carbon yield of the pyrolysis products from birch and spruce feedstock

Table 2. Pyrolysis Gas Composition

\begin{tabular}{|c|c|c|c|c|c|c|c|}
\hline Feedstock & $\begin{array}{c}\mathrm{CO}_{2} \\
(\mathrm{~mol} \%)\end{array}$ & $\begin{array}{c}\mathrm{CO} \\
(\mathrm{mol} \%)\end{array}$ & $\begin{array}{c}\text { Methane } \\
(\mathrm{mol} \%)\end{array}$ & $\begin{array}{c}\text { Ethylene } \\
(\mathrm{mol} \%)\end{array}$ & $\begin{array}{c}\text { Ethane } \\
(\mathrm{mol} \%)\end{array}$ & $\begin{array}{c}\text { Propane+ } \\
\text { propylene } \\
(\mathrm{mol} \%)\end{array}$ & $\begin{array}{c}\mathrm{H}_{2} \\
(\mathrm{~mol} \%)\end{array}$ \\
\hline $\begin{array}{c}\text { Birch } \\
400^{\circ} \mathrm{C}\end{array}$ & 55.9 & 33.2 & 7.8 & 0.7 & 1.0 & 0.4 & 1.0 \\
\hline $\begin{array}{c}\text { Birch } \\
550^{\circ} \mathrm{C}\end{array}$ & 37.7 & 36.5 & 16.4 & 1.2 & 1.7 & 1.1 & 5.4 \\
\hline $\begin{array}{c}\text { Spruce } \\
400^{\circ} \mathrm{C}\end{array}$ & 50.3 & 37.2 & 9.1 & 0.7 & 1.3 & 0.5 & 0.9 \\
\hline $\begin{array}{c}\text { Spruce } \\
550^{\circ} \mathrm{C}\end{array}$ & 35.5 & 38.7 & 15.9 & 1.2 & 1.5 & 0.8 & 6.4 \\
\hline
\end{tabular}

Table 2 shows the molar gas composition of the four pyrolysis experiments. The primary gas produced at $400{ }^{\circ} \mathrm{C}$ was $\mathrm{CO}_{2}$, followed by $\mathrm{CO}, \mathrm{C} 1$ to $\mathrm{C} 3$ hydrocarbons, and $\mathrm{H}_{2}$. Pyrolysis at $550{ }^{\circ} \mathrm{C}$ reduced the amount of the produced $\mathrm{CO}_{2}$ fraction for both birch and spruce compared to pyrolysis at $400{ }^{\circ} \mathrm{C}$. The other gas fractions were enriched as the pyrolysis temperature increased, resulting in a higher energy content of the pyrolysis gas. 
The gas fraction can be combusted for process energy purposes, but the moisture content can limit the feasibility. Another possible application for the pyrolysis gas is to recycle the gas back into the process (Dhyani and Bhaskar 2018).

More carbon was retained in the birch aqueous condensates than the spruce aqueous condensates at the corresponding temperatures, as shown by the carbon balance depicted in Fig. 4. This is most likely due to the higher hemicellulose content in birch (Dhyani and Bhaskar 2018). Hemicelluloses are expected to promote an increase in yield of the aqueous condensate since they degrade at lower temperatures than cellulose and lignins (Yang et al. 2007). The spruce aqueous condensates were also more opaque than the birch aqueous phases, as shown in Fig. 5. This indicated a higher water content and less concentrated carbon-containing substances in the spruce aqueous phases. This was confirmed by the water content measurements and elemental analysis, which is shown in Table 3 . The high amount of carbon retained in the aqueous phases emphasizes the need for a suitable anaerobic digestion process to complement the pyrolysis process to achieve high carbon utilization.

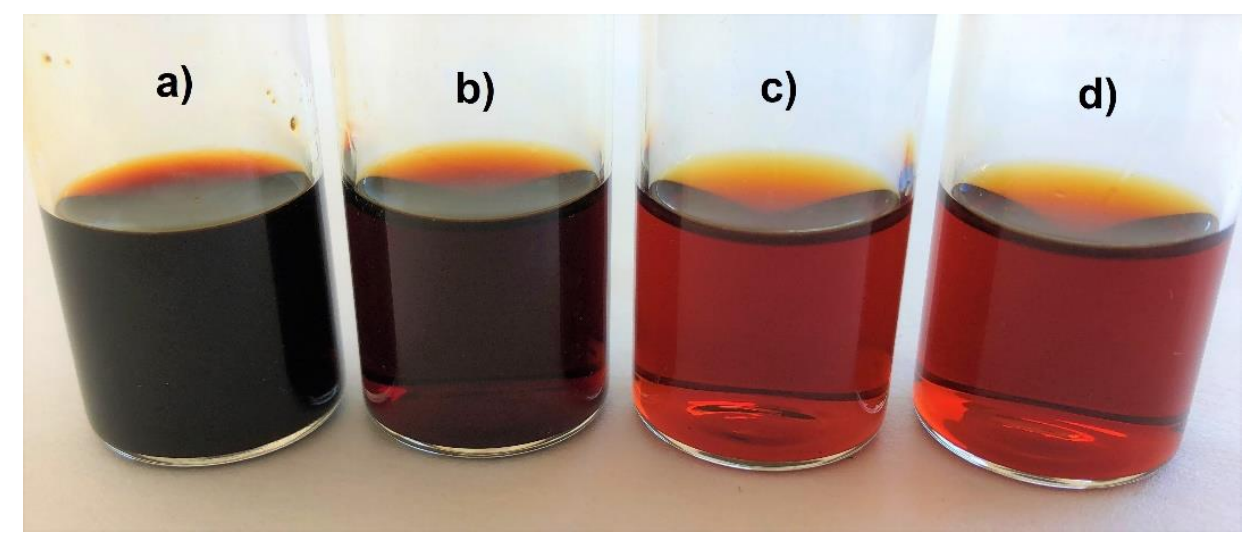

Fig. 5. Aqueous condensate samples for anaerobic digestion: a) Birch $400{ }^{\circ} \mathrm{C}$; b) Birch $550^{\circ} \mathrm{C}$; c) Spruce $400{ }^{\circ} \mathrm{C}$; and d) Spruce $550^{\circ} \mathrm{C}$

\section{Effect of the Pyrolysis Temperature on the Biomethane Yield During Anaerobic Digestion}

The aqueous condensate from the pyrolysis, used as feedstock in AD, showed methane yields in the APL ranging from 112 to $207 \mathrm{NmL} / \mathrm{gCOD}$, depending on the type of biomass and the pyrolysis temperature (Table 3). The APL from birch pyrolysis at a temperature of 400 and $550{ }^{\circ} \mathrm{C}$ had a biomethane yield of $44 \%$ and $49 \%$ of the theoretical achievable yield, respectively. A small increase in yield was observed with an increase in pyrolysis temperature for birch. Contrarily, a large decrease in methane yield, from 59\% to $32 \%$, was observed in the APL of spruce as the pyrolysis temperature increased from 400 to $550{ }^{\circ} \mathrm{C}$. A decrease in methane yield from APL as the pyrolysis temperature increases has also been observed in previous studies (Erdogan et al. 2015; Hübner and Mumme 2015). A common trend in both birch and spruce is a decrease in methane yield as the carbon content increases in the APL (Fig. 6). An increase in pyrolysis temperature reduces the concentrations of easily degradable ketones and acids in the APL, while forming higher concentrations of recalcitrant or toxic carbon compounds, e.g., hydroxyacetaldehyde, acetol, furans, N-heterocyclic compounds, and phenols inhibiting bacteria and archaea, thus hampering the AD (Hierholtzer et al. 2013; Alvarez et al. 2014; Rezaei et al. 2014). 
Table 3. Aqueous Phase Parameters and Anaerobic Digestion Results

\begin{tabular}{|c|c|c|c|c|c|}
\hline \multirow{2}{*}{ Feedstock } & \multirow{2}{*}{$\begin{array}{c}\text { Water } \\
\text { Content } \\
\text { (wt\%) }\end{array}$} & \multicolumn{2}{|c|}{$\begin{array}{l}\text { Carbon Content } \\
\text { (wt\%) }\end{array}$} & \multirow{2}{*}{$\begin{array}{l}\text { COD } \\
(g / L)\end{array}$} & \multirow{2}{*}{$\begin{array}{c}\text { Methane Yield } \\
(\mathrm{gCOD} / \mathrm{gCOD}) /(\mathrm{NmL} / \mathrm{gCOD})\end{array}$} \\
\hline & & $\begin{array}{l}\text { Wet } \\
\text { basis }\end{array}$ & Dry basis & & \\
\hline Birch $400^{\circ} \mathrm{C}$ & 46.5 & 28.0 & 52.2 & $703 \pm 4$ & $0.44 \pm 0.01 / 152 \pm 4$ \\
\hline Birch $550^{\circ} \mathrm{C}$ & 57.1 & 21.2 & 49.6 & $556 \pm 3$ & $0.49 \pm 0.03 / 172 \pm 8$ \\
\hline Spruce $400^{\circ} \mathrm{C}$ & 67.8 & 14.7 & 45.5 & $432.5 \pm 0.7$ & $0.59 \pm 0.02 / 207 \pm 10$ \\
\hline Spruce $550^{\circ} \mathrm{C}$ & 66.8 & 15.3 & 46.1 & $445 \pm 1$ & $0.32 \pm 0.03 / 112 \pm 11$ \\
\hline
\end{tabular}

The carbon content had a large effect on the methane yield when using spruce (softwood). This is believed to be an effect of the high lignin content of Norway spruce (27.6 wt\% to 29.4 wt\% dry basis) (Părpăriţă et al. 2014). This leads to a higher concentration of complex phenols with higher molecular weights and an increased carbon content in spruce bio-oil (Stefanidis et al. 2014). In contrast, the carbon content had little effect on the methane yield when using birch (hardwood), although there was a major difference in the carbon content between the APLs pre-treated at different temperatures. This is explained by the lower lignin content ( $21 \mathrm{wt} \%$ dry basis) and by the more complex lignin structures in hardwood (syringil-guaiacyl lignin) compared to softwood (guaiacyl lignin) (Fahmi et al. 2008; Părpăriță et al. 2014). The more complex lignins found in hardwoods have a lower decomposition rate, which yields less inhibitory APL (Torri et al. 2016).

The methane yield will likely be higher in a continuous AD process compared to batch tests, as it allows for the microorganisms to adapt to the inhibitors present in the APL (Torri and Fabbri 2014). In addition, dilution and the addition of additives, e.g., biochar, can also enhance AD and increase the methane yield (Torri and Fabbri 2014).

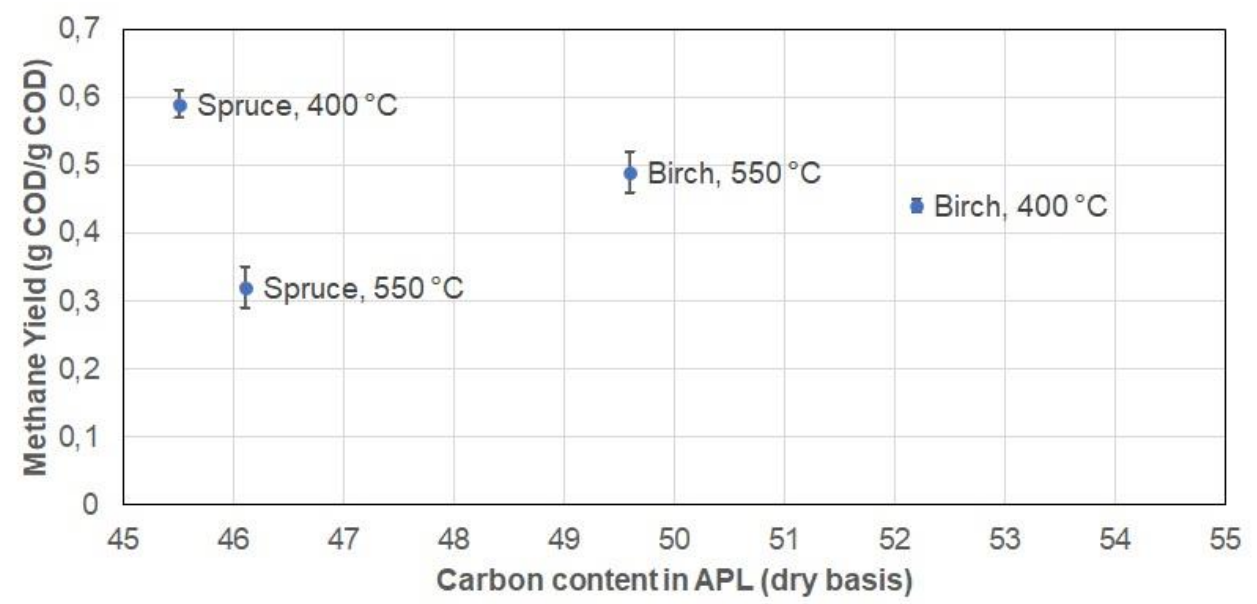

Fig. 6. Methane yield decreases as the carbon content increases in APL

\section{Overall Carbon Balance for the Current System}

Figure 7 compares the combined utilized carbon yield for the four experiments with the chosen benchmark (52.1\% carbon yield for conventional charcoal production), i.e., the "hot tail" kiln. The utilized carbon yield contains all the carbon yields from the fractions obtained that can be further used, either as transportation fuel, an energy carrier, or a 
reducing agent. It contains the carbon yields of the biocarbon from pyrolysis, which can be used as a reducing agent; the biomethane yield produced via the AD of APL, which can be used as transportation fuel; and the organic condensate and combustible carbon-containing gasses generated during pyrolysis, which can be used as energy carriers. In addition, $\mathrm{H}_{2}$ gas is produced in various amounts during pyrolysis, especially during a higher temperature pyrolysis process. The $\mathrm{H}_{2}$ adds to the energy content of the generated pyrolysis gas but is not included here.

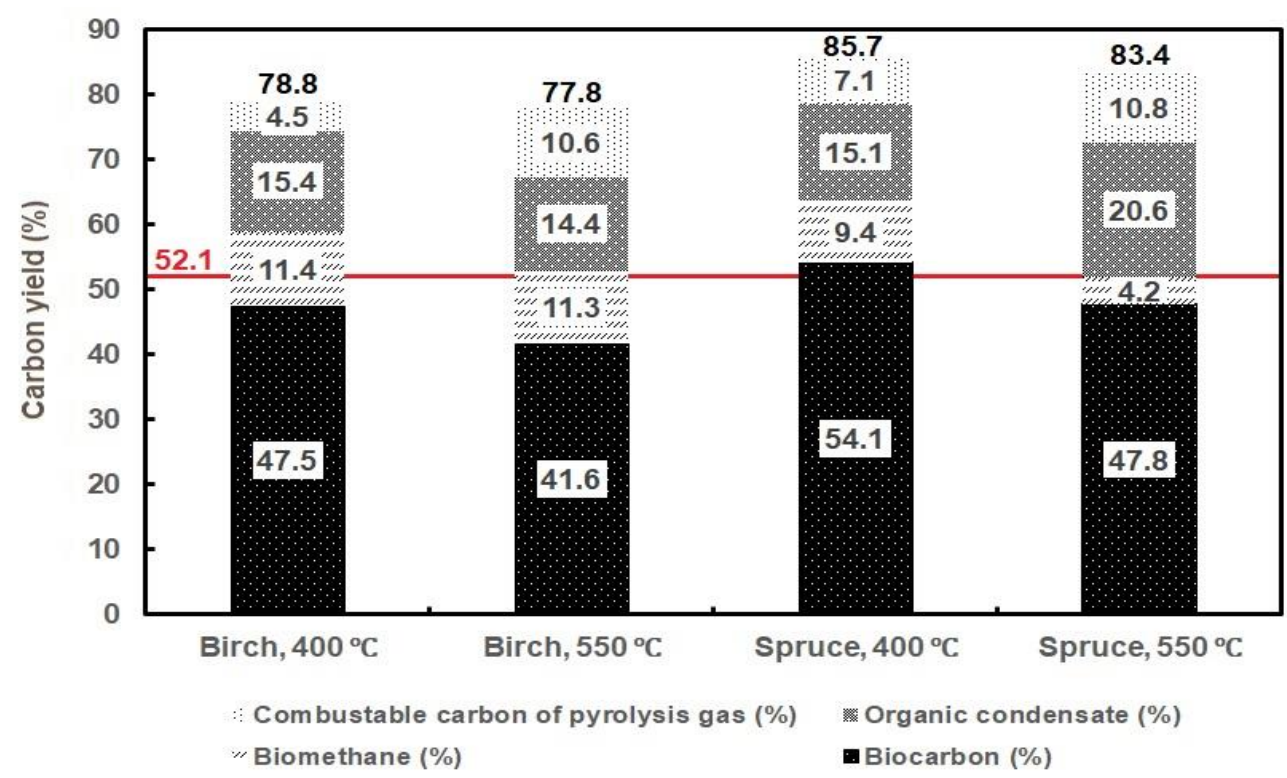

Fig. 7. Utilization of the carbon from the different fractions when combining pyrolysis and anaerobic digestion (Note: the red line located at $52.1 \%$ is the chosen benchmark for comparison)

All four systems yielded higher carbon utilization than the benchmark, i.e., a 52.1\% carbon utilisation of the "hot tail" kiln. Birch wood obtained combined carbon utilization yields of $78.8 \%$ and $77.8 \%$ for pyrolysis temperatures of 400 and $550{ }^{\circ} \mathrm{C}$, respectively. Spruce wood obtained slightly higher combined carbon utilization yields of $83.4 \%$ and $82.7 \%$ for pyrolysis temperatures of 400 and $550{ }^{\circ} \mathrm{C}$, respectively. The primary factor for the lower total carbon yields of birch wood is the unconverted carbon in AD. Although obtaining reasonable biomethane yields for batch conversion, with $44 \%$ and $49 \%$ from APL from birch pyrolyzed at 400 and $550{ }^{\circ} \mathrm{C}$, respectively, the high carbon retention in the ALP of birch results in considerable carbon losses due to the unconverted carbon from AD. A greater amount of total utilized carbon was obtained from spruce than birch, even though the biomethane contribution was quite small for spruce, especially for spruce pyrolyzed at $550{ }^{\circ} \mathrm{C}$, due to the low carbon retention in the aqueous condensate from spruce pyrolysis.

The carbon losses identified for the combined system are shown in Fig. 8. The two primary carbon losses are $\mathrm{CO}_{2}$ generation during pyrolysis and the unconverted carbon during AD. The largest carbon loss in all cases was the unconverted carbon in the APL, except for spruce pyrolyzed at $400{ }^{\circ} \mathrm{C}$, which had the highest loss due to its biomethane yield of 59\%. The other experiments performed carbon recovery on biomethane yields of less than $50 \%$. Developing efficient AD processes with adapted microorganisms should be carried out to further increase the overall carbon utilization. The carbon loss to $\mathrm{CO}_{2}$ was similar for birch and spruce wood pyrolyzed at a temperature of 400 and $550{ }^{\circ} \mathrm{C}$. 


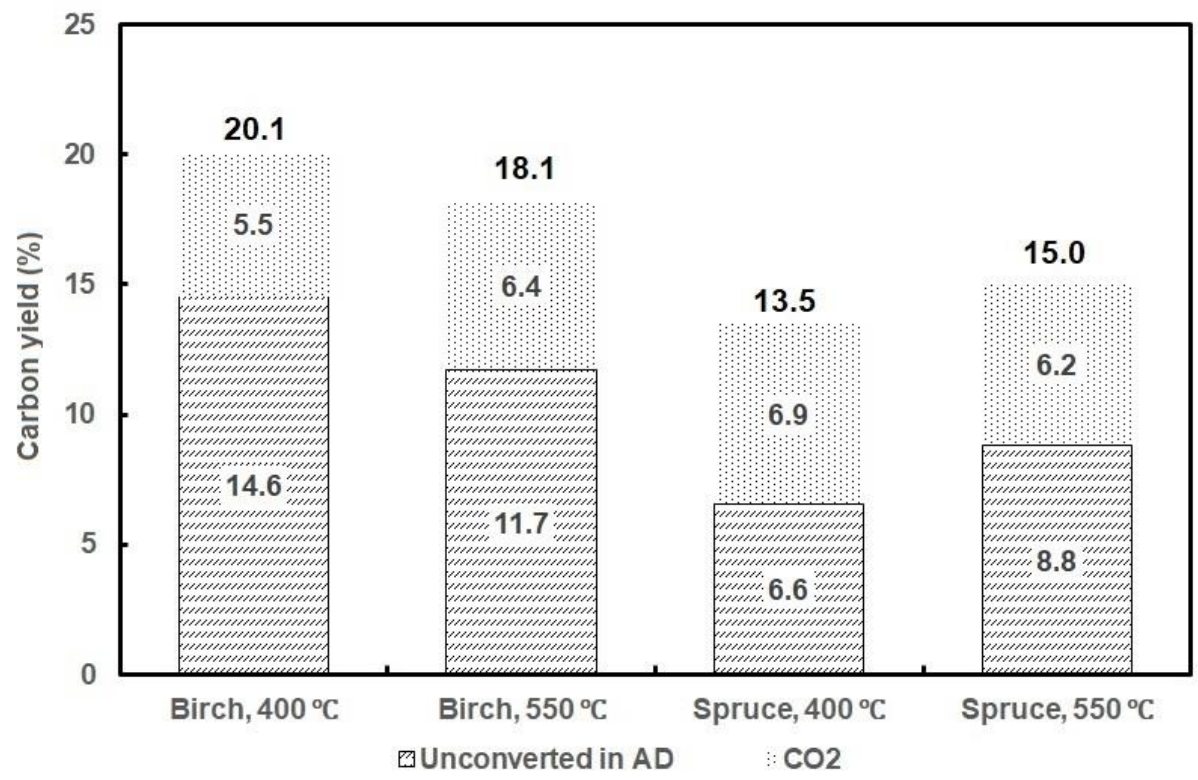

Fig. 8. Carbon losses of the combined system of intermediate pyrolysis and anaerobic digestion

The biochar from spruce pyrolyzed at $400{ }^{\circ} \mathrm{C}$ attained a carbon yield of $54.1 \%$, which exceeded the chosen benchmark of $52.1 \%$. The high carbon yield of biochar from spruce might be due to the higher expected yield from conifers, as previously discussed. Nevertheless, substantial amounts of biocarbon were still produced in the other three experiments. This shows that with a small sacrifice in biocarbon yield, biocarbon can be produced with much shorter process times via intermediate pyrolysis compared to conventional charcoal production. In addition, intermediate pyrolysis allows for the collection and utilization of viable side streams to obtain increased carbon utilization by generating energy carriers, organic condensate, and pyrolysis gas, as well as producing transportation fuel, e.g., biomethane, via the AD of APL.

\section{CONCLUSIONS}

1. Intermediate pyrolysis enhances the carbon utilization potential compared to conventional charcoal production methods if all fractions produced during pyrolysis are utilized.

2. Spruce wood has a higher inherent potential for high biochar yields compared to birch wood, while birch has higher carbon retention in the aqueous condensate (APL). Thus, birch is more dependent on good carbon recovery in terms of producing biomethane via anaerobic digestion for high total carbon utilization.

3. As shown in batch experiments, anaerobic digestion may be used to recover reasonable amounts of carbon in the form of biomethane from the aqueous condensate from the intermediate pyrolysis of wood. This shows the potential for high carbon recovery from APL with well-adapted microorganisms, continuous systems, and enhancing additives.

4. A decrease in biomethane yield was observed in spruce wood as the pyrolysis temperature increased, which may be explained the increased formation of inhibitors from softwood lignins. A decrease in biomethane yield was not observed as the 
pyrolysis temperature increased for birch wood.

5. A decrease in methane yield with an increased carbon content in the APL was observed for both birch and spruce wood. The effect was largest in spruce and was associated with the less complex softwood lignins, leading to higher concentrations of recalcitrant and toxic compounds in the intermediate pyrolysis APL.

\section{ACKNOWLEDGMENTS}

The current work was funded through the following projects: Pyrogas (Project No. 269322), EnergiX, the Research Council of Norway, project owner Norske Skog Saugbrugs and Norwegian Centre for Sustainable Bio-based Fuels and Energy; and Bio4Fuels (Project No. 257622), the Research Council of Norway. The pyrolysis development unit used in this study is a part of the national infrastructure NorBioLab financed by the Research Council of Norway.

\section{REFERENCES CITED}

Alvarez, J., Lopez, G., Amutio, M., Bilbao, J., and Olazar, M. (2014). "Bio-oil production from rice husk fast pyrolysis in a conical spouted bed reactor," Fuel 128, 162-169. DOI: 10.1016/j.fuel.2014.02.074

Antal, M. J., and Grønli, M. (2003). "The art, science, and technology of charcoal production," Industrial \& Engineering Chemistry Research 42(8), 1619-1640. DOI: 10.1021/ie0207919

American Public Health Association (APHA) (1995). "Standard methods 5220D: Chemical oxygen demand," in Standard Methods for the Examination of Water and Wastewater, Washington DC, USA.

Appels, L., Baeyens, J., Degrève, J., and Dewil, R. (2008). "Principles and potential of the anaerobic digestion of waste-activated sludge," Progress in Energy and Combustion Science 34(6), 755-781. DOI: 10.1016/j.pecs.2008.06.002

Appels, L., Lauwers, J., Degrève, J., Helsen, L., Lievens, B., Willems, K., Impe, J. V., and Dewil, R. (2011). "Anaerobic digestion in global bio-energy production: Potential and research challenges," Renewable and Sustainable Energy Reviews 15(9), 4295-4301. DOI: 10.1016/j.rser.2011.07.121

Badshah, M., Lam, D. M., Liu, J., and Mattiasson, B. (2012). "Use of an automatic methane potential test system for evaluating the biomethane potential of sugarcane bagasse after different treatments," Bioresour Technology 114, 262-269. DOI: 10.1016/j.biortech.2012.02.022

Baeta, B. E. L., Luna, H. J., Sanson, A. L., Silva, S. Q., and Aquino, S. F. (2013). "Degradation of a model azo dye in submerged anaerobic membrane bioreactor (SAMBR) operated with powdered activated carbon (PAC)," Journal of Environmental Management 128, 462-70. DOI: 10.1016/j.jenvman.2013.05.038

Bailis, R. (2009). "Modeling climate change mitigation from alternative methods of charcoal production in Kenya," Biomass and Bioenergy 33(11), 1491-1502. DOI: 10.1016/j.biombioe.2009.07.001

Bailis, R., Ezzati, M., and Kammen, D. M. (2005). "Mortality and greenhouse gas 
impacts of biomass and petroleum energy futures in Africa," Science 308(5718), 98103. DOI: $10.1126 /$ science. 1106881

Bailis, R., Rujanavech, C., Dwivedi, P., Vilela, A. d. O., Chang, H., and de Miranda, R. C. (2013). "Innovation in charcoal production: A comparative life-cycle assessment of two kiln technologies in Brazil," Energy for Sustainable Development 17(2), 189 200. DOI: 10.1016/j.esd.2012.10.008

Benjamin, M. M., Woods, S. L., and Ferguson, J. F. (1984). "Anaerobic toxicity and biodegradability of pulp mill waste constituents," Water Research 18(5), 601-607. DOI: 10.1016/0043-1354(84)90210-0

Bridgwater, A. V. (2012). "Review of fast pyrolysis of biomass and product upgrading," Biomass and Bioenergy 38, 68-94. DOI: 10.1016/j.biombioe.2011.01.048

Cha, J. S., Park, S. H., Jung, S.-C., Ryu, C., Jeon, J.-K., Shin, M.-C., and Park, Y.-K. (2016). "Production and utilization of biochar: A review," Journal of Industrial and Engineering Chemistry 40, 1-15. DOI: 10.1016/j.jiec.2016.06.002

Dhyani, V., and Bhaskar, T. (2018). "A comprehensive review on the pyrolysis of lignocellulosic biomass," Renewable Energy 129(Part B), 695-716. DOI: 10.1016/j.renene.2017.04.035

Erdogan, E., Atila, B., Mumme, J., Reza, M. T., Toptas, A., Elibol, M., and Yanik, J. (2015). "Characterization of products from hydrothermal carbonization of orange pomace including anaerobic digestibility of process liquor," Bioresour Technology 196, 35-42. DOI: 10.1016/j.biortech.2015.06.115

Fabbri, D., and Torri, C. (2016). "Linking pyrolysis and anaerobic digestion (Py-AD) for the conversion of lignocellulosic biomass," Current Opinion in Biotechnology 38, 167-173. DOI: 10.1016/j.copbio.2016.02.004

Fahmi, R., Bridgwater, A. V., Donnison, I., Yates, N., and Jones, J. M. (2008). “The effect of lignin and inorganic species in biomass on pyrolysis oil yields, quality and stability," Fuel 87(7), 1230-1240. DOI: 10.1016/j.fuel.2007.07.026

Feng, Q., and Lin, Y. (2017). "Integrated processes of anaerobic digestion and pyrolysis for higher bioenergy recovery from lignocellulosic biomass: A brief review," Renewable Sustainable Energy Rev. 77, 1272-1287. DOI: 10.1016/j.rser.2017.03.022

Hierholtzer, A., Chatellard, L., Kierans, M., Akunna, J. C., and Collier, P. J. (2013). "The impact and mode of action of phenolic compounds extracted from brown seaweed on mixed anaerobic microbial cultures," Journal of Applied Microbiology 114(4), 964973. DOI: $10.1111 /$ jam.12114

Hübner, T., and Mumme, J. (2015). "Integration of pyrolysis and anaerobic digestion Use of aqueous liquor from digestate pyrolysis for biogas production," Bioresource Technology 183, 86-92. DOI: 10.1016/j.biortech.2015.02.037

Kan, X., Yao, Z., Zhang, J., Tong, Y. W., Yang, W., Dai, Y., Wang, C.-H. (2017). "Energy performance of an integrated bio-and-thermal hybrid system for lignocellulosic biomass waste treatment," Bioresour Technology 228, 77-88. DOI: 10.1016/j.biortech.2016.12.064

Khalid, A., Arshad, M., Anjum, M., Mahmood, T., and Dawson, L. (2011). “The anaerobic digestion of solid organic waste," Waste Management 31(8), 1737-1744. DOI: 10.1016/j.wasman.2011.03.021

Laird, D. A., Brown, R. C., Amonette, J. E., and Lehmann, J. (2009). "Review of the pyrolysis platform for coproducing bio-oil and biochar," Biofuels, Bioproducts and Biorefining 3(5), 547-562. DOI: 10.1002/bbb.169

Maschio, G., Koufopanos, C., and Lucchesi, A. (1992). "Pyrolysis, a promising route for 
biomass utilization," Bioresource Technology 42(3), 219-231. DOI: 10.1016/09608524(92)90025-S

Părpăriţă, E., Brebu, M., Uddin, A., Yanik, J., and Vasile, C. (2014). "Pyrolysis behaviors of various biomasses," Polymer Degradation and Stability 100, 1-9. DOI:

10.1016/j.polymdegradstab.2014.01.005

Pennise, D. M., Smith, K. R., Kithinji, J. P., Rezende, M. E., Raad, T. J., Zhang, J., and Fan, C. (2001). "Emissions of greenhouse gases and other airborne pollutants from charcoal making in Kenya and Brazil," Journal of Geophysical Research: Atmospheres 106(D20), 24143-24155. DOI: 10.1029/2000JD000041

Rezaei, P. S., Shafaghat, H., and Daud, W. M. A. W. (2014). "Production of green aromatics and olefins by catalytic cracking of oxygenate compounds derived from biomass pyrolysis: A review," Applied Catalysis A: General 469, 490-511. DOI: 10.1016/j.apcata.2013.09.036

Stefanidis, S. D., Kalogiannis, K. G., Iliopoulou, E. F., Michailof, C. M., Pilavachi, P. A., and Lappas, A. A. (2014). "A study of lignocellulosic biomass pyrolysis via the pyrolysis of cellulose, hemicellulose and lignin," Journal of Analytical and Applied Pyrolysis 105, 143-150. DOI: 10.1016/j.jaap.2013.10.013

Torri, C., and Fabbri, D. (2014). "Biochar enables anaerobic digestion of aqueous phase from intermediate pyrolysis of biomass," Bioresour Technology 172, 335-341. DOI: 10.1016/j.biortech.2014.09.021

Torri, I. D. V., Paasikallio, V., Faccini, C. S., Huff, R., Caramão, E. B., Sacon, V., Oasmaa, A., and Zini, C. A. (2016). "Bio-oil production of softwood and hardwood forest industry residues through fast and intermediate pyrolysis and its chromatographic characterization," Bioresour Technology 200, 680-690. DOI: 10.1016/j.biortech.2015.10.086

Vasco-Correa, J., Khanal, S., Manandhar, A., and Shah, A. (2018). "Anaerobic digestion for bioenergy production: Global status, environmental and techno-economic implications, and government policies," Bioresource Technology 247, 1015-1026. DOI: 10.1016/j.biortech.2017.09.004

Wenzl, H. (2012). The Chemical Technology of Wood, Academic Press, Cambridge, MA. Yang, H., Yan, R., Chen, H., Lee, D. H., and Zheng, C. (2007). "Characteristics of hemicellulose, cellulose and lignin pyrolysis," Fuel 86(12-13), 1781-1788. DOI: 10.1016/j.fuel.2006.12.013

Yang, L., Xu, F., Ge, X., and Li, Y. (2015). "Challenges and strategies for solid-state anaerobic digestion of lignocellulosic biomass," Renewable and Sustainable Energy Reviews 44, 824-834. DOI: 10.1016/j.rser.2015.01.002

Yang, Y., Brammer, J. G., Mahmood, A. S. N., and Hornung, A. (2014). "Intermediate pyrolysis of biomass energy pellets for producing sustainable liquid, gaseous and solid fuels," Bioresource Technology 169, 794-799. DOI:

10.1016/j.biortech.2014.07.044

Zhou, H., Brown, R. C., and Wen, Z. (2019). "Anaerobic digestion of aqueous phase from pyrolysis of biomass: Reducing toxicity and improving microbial tolerance," Bioresource Technology 292, 121976. DOI: 10.1016/j.biortech.2019.121976

Article submitted: December 18, 2020; Peer review completed: March 20, 2021; Revised version received and accepted: April 9, 2021; Published: April 16, 2021.

DOI: 10.15376/biores.16.2.3964-3977 